\title{
Outcome and long-term efficacy of four facio-cervical fields conformal radiotherapy for nasopharyngeal carcinoma
}

\author{
Wang Fangzheng ${ }^{1,2, *}$, Jiang Chuner ${ }^{3, *}$, Wang Lei $^{1,2}{ }$, Chen Weijun ${ }^{1,2}$, Xu Min ${ }^{1,2}$, Sun \\ Quanquan ${ }^{1,2}$, Liu Tongxin ${ }^{1,2}$, Rihito Aizawa ${ }^{4}$, Masoto Sakamoto ${ }^{4}$, Fu Zhenfu ${ }^{1,2}$ \\ ${ }^{1}$ Department of Radiation Oncology, Zhejiang Cancer Hospital, Zhejiang Hangzhou, 310022 China \\ ${ }^{2}$ Zhejiang Key Laboratory of Radiation Oncology, Zhejiang Hangzhou, 310022 China \\ ${ }^{3}$ Department of Breast Surgery, Zhejiang Cancer Hospital, Zhejiang Hangzhou, 310022 China \\ ${ }^{4}$ Department of Radiology, Japanese Red Cross Fukui Hospital, Fukui, 918-8501 Japan \\ "These authors have contributed equally to this work
}

Correspondence to: Wang Fangzheng, email: wangfz76@126.com

Keywords: nasopharyngeal neoplasm, conformal radiotherapy, chemotherapy, efficacy, prognosis

Received: August 19, $2016 \quad$ Accepted: December 27, $2016 \quad$ Published: December 31, 2016

Copyright: Wang Fangzheng et al. This is an open-access article distributed under the terms of the Creative Commons Attribution License 3.0 (CC BY 3.0), which permits unrestricted use, distribution, and reproduction in any medium, provided the original author and source are credited.

\section{ABSTRACT}

Purpose: To evaluate the outcomes of 255 patients with nasopharyngeal carcinoma (NPC) treated with four facio-cervical fields conformal radiotherapy (4F-CRT).

Results: In one patient's 3 different RT treatment modalities, the 4F-CRT techniques resulted in sharper of the dose-volume histograms (DVHs) for primary gross tumor volume (PGTVnx) and planning target volume (PTVnx), similar to the intensity modulated radiation therapy (IMRT). The median follow-up duration was $\mathbf{4 3}$ months. Locoregional relapse and distant metastases as the first treatment failure events occurred in 32 $(32 / 255,12.5 \%)$ and $20(30 / 255,11.8 \%)$ patients, respectively. The 3-year and 5-year local control, disease-free survival, and overall survival rates were $83.3 \%$, $82 \%$, $83.8 \%$, and $76.1 \%, 73.2 \%, 76.3 \%$ respectively. Univariate analysis displayed that clinical stage, $\mathrm{T}$-stage, $\mathrm{N}$-stage, and tumor response were related to prognosis. Multivariate analysis indicated that age, $\mathrm{T}$-stage, $\mathrm{N}$-stage, and combined chemotherapy were independent prognosticators. The incidence of grade 1-2 acute mucositis and leukocytopenia were $93.7 \%$ and $91.0 \%$, respectively, with no cases of grade 4 toxicity detected.

Materials and Methods: From November 2007 to December 2011, 255 patients with histologically diagnosed, non-metastatic NPC were enrolled into this study and received 4F-CRT. Magnetic resonance imaging scans of the nasopharynx were performed on every patient. All patients received definitive radiotherapy with $6 \mathrm{MV}$ $X$-rays using conventional fractions at 2 Gy daily, 5 fractions per week, and 231 patients with stage IIb-IV received concurrent chemotherapy and cisplatin-based adjuvant chemotherapy. The accumulated survival was calculated according to the Kaplan-Meier method; the log-rank test was used to compare survival differences. Multivariate analysis was performed using Cox's proportional hazard model.

Conclusions: Compared with the conventional treatment plans, the 4F-CRT plan delivered more dose to cover the tumor volume and reduces the doses of the normal tissues including the parotid gland, TMJs and so on. The long-term efficacy of 4F-CRT is satisfactory and its toxicities are tolerable.

\section{INTRODUCTION}

Nasopharyngeal carcinoma (NPC) is one of the most common malignant tumors in Southern China $[1,2]$.
Owing to its anatomic location and high radiosensitivity, radiotherapy (RT) has long been as the preferred method of treatment for NPC. Conventional 2-dimensional radiotherapy (2D-RT) had been used as the most common method. Early 
literatures reported that the 5-year overall survival rates of stages I, II, III, and IV were 70-95\%, 65-83\%, 54-76\%, and $29-56 \%$, respectively [3-7]. With increasing in the number of survivors with NPC, more patients are experiencing various radiation related complications $[8,9]$, such as serious mouth dry, trismus, inner ear hearing loss, and brain injury, which decreased their quality of life.

Intensity modulated radiation therapy (IMRT), as a new approach, is preformed to the treatment planning and delivered the radiation for patients with cancer $[10,11]$. Compared with 2D-RT and 3-dimensional radiotherapy (3D-CRT), IMRT improves the conformal dose covered the clinical target volume (CTV) in three dimensions, while protecting the normal tissues around the CTV. Recently published phase III studies indicated that IMRT has better curative effect and lower toxicity than with conventional 2D-RT or 3D-CRT $[12,13]$. Therefore, IMRT is the first choice of radiotherapy for nasopharyngeal carcinoma because of its dosimetric advantages. However, there were more and more NPC patients in our hospital and only the current machines are not enough to meet all the NPC patients received IMRT. In order to overcome this difficulty,

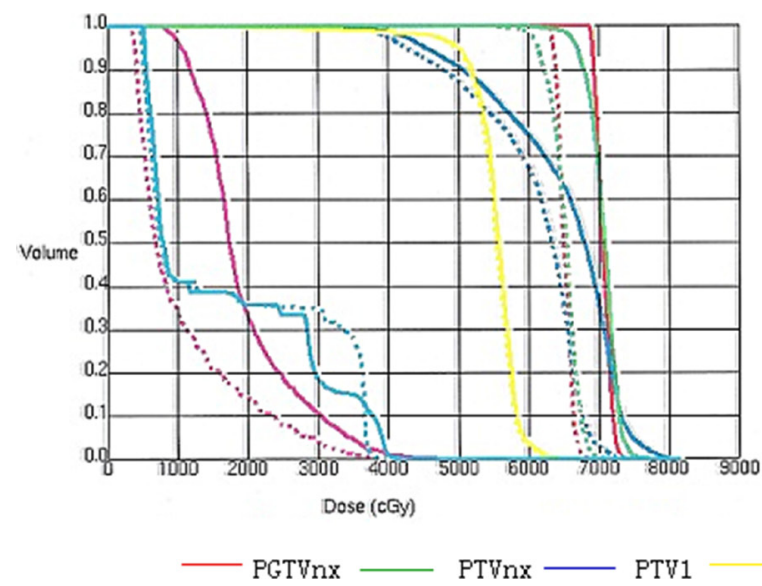

the author designed a method of the four facio-cervical fields conformal radiotherapy (4F-CRT) to treat patients with NPC [14] and applied this method in clinical practice according to the actual situation of the hospital. The purpose of our study was to analyze the long-term efficacy among 255 patients with NPC who received 4F-CRT in our hospital.

\section{RESULTS}

\section{Plan comparison}

One patient out of 255 underwent 3 different RT treatment modalities. The plans included 2D-RT, 4F-CRT, and IMRT. The DVHs of targets, brain stem, and spinal cord were shown in Figure 1. The sharper DVHs for primary gross tumor volume (PGTVnx) and planning target volume (PTVnx) of the 4F-CRT techniques were similar to those of the IMRT. Among the three plans, the mean doses of $\mathrm{D}_{\max }$ received by spinal cord and brain stem were within safety limits. The DVHs of three plans for the parotid gland, temporomandibular joint (TMJ), inner ear, and temporal lobe were reported in Figure 2. Compared

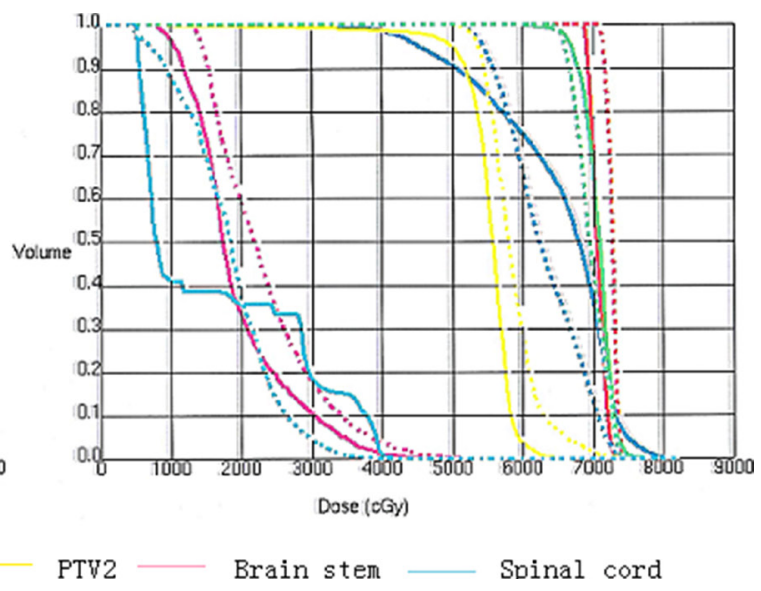

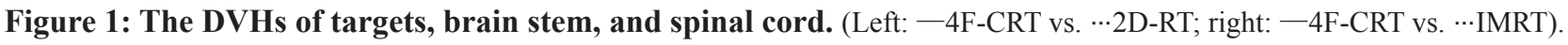
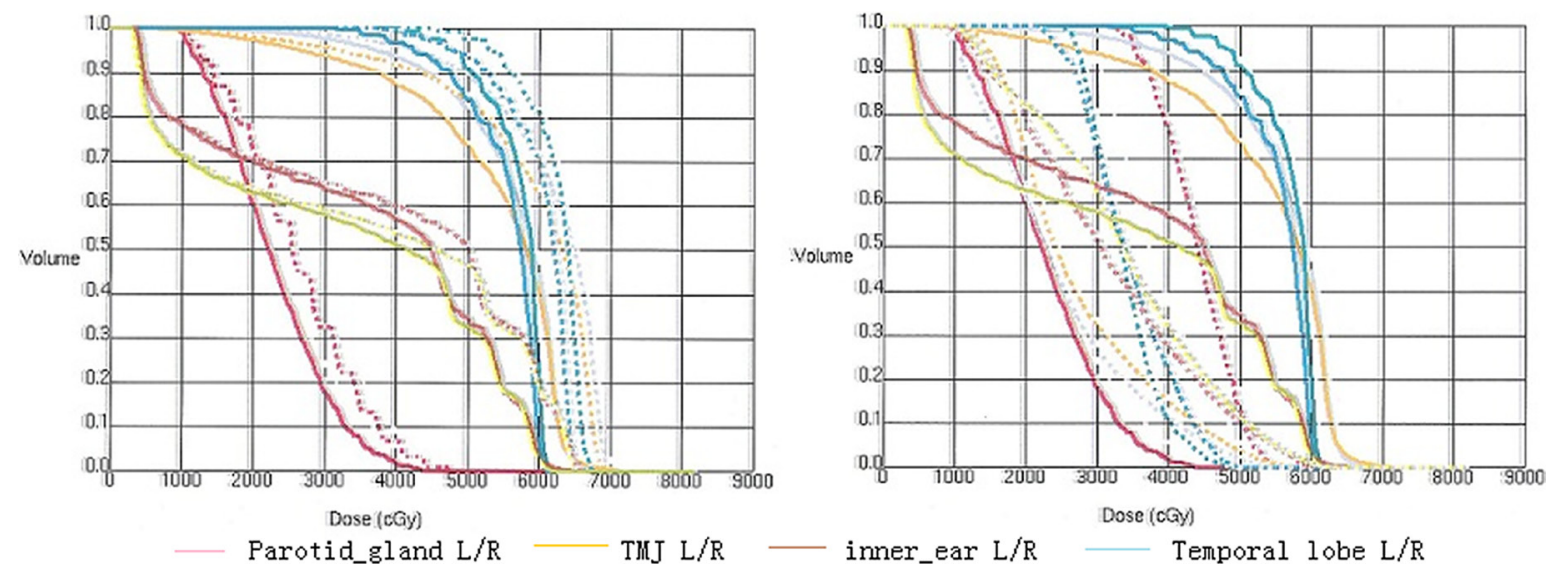

Figure 2: The DVHs for the parotid gland, temporomandibular joint (TMJ), inner ear, and temporal lobe. (Left: -4F-CRT vs. ‥2D-RT; right: -4F-CRT vs. ‥IMRT). 
with the conventional 2D-RT plans, the 4F-CRT plan delivered lower dose to the OARs and protected parotid gland, TMJ, inner ear, and temporal lobe to avoid severe damage. However, there were more hotspot areas in the OARs for 4F-CRT than for IMRT.

\section{Response of tumor}

The overall response rates for lesions of nasopharynx and cervical lymph nodes were 100\% (complete remission [CR] 82.5\%) and 100\% (CR 95.7\%) 3 months after completing RT, respectively.

\section{Treatment outcome and failure patterns}

All patients completed the $4 \mathrm{~F}-\mathrm{CRT}$. The median follow-up was 43 (range, 8-79) months and 103 patients survived for more than five years. The threeyear estimated local recurrence-free survival (LRFS), progression-free survival (PFS), and overall survival (OS) rates were $83.3 \%, 82 \%$, and $82.8 \%$, respectively. The five-year estimated LRFS, PFS, and OS rates were $73.2 \%, 76.3 \%$, and $76.1 \%$, respectively. The overall 5-year LRFS rates for the patients were 100\%, $82.5 \%, 76 \%$, and $54.9 \%$ for stage $\mathrm{T} 1, \mathrm{~T} 2, \mathrm{~T} 3$, and $\mathrm{T} 4$, respectively $(\log -$ rank $=46.882, P<0.001)$ (Figure 3$)$. The overall five-year distant metastasis-free survival (DMFS) rates for the patients were 100\%, 94.1\%, $85.5 \%$, and $62.5 \%$ for stage I, II, III and IV, respectively $(\log$-rank $=21.217, P<0.001)($ Figure 4$)$.

Of all patients, 62 patients experienced treatment failure: 18 patients had local recurrence only; 10 developed regional relapse only and received salvage surgery; 4 had locoregional recurrence; 25 developed $\geq 1$ distant metastasis, all of whom died from disease progression; and 5 patients occurred with locoregional relapse and distant metastasis. These details are shown in Table 1.

\section{Risk factors analysis}

Potential prognostic factors, including age, gender, histology, clinical stage, $\mathrm{T}$ classification, $\mathrm{N}$ classification, combined chemotherapy, blood group, weight loss, comorbidity, and tumor response, were evaluated using univariate analysis and Cox proportional hazards models. Univariate analysis revealed that $\mathrm{T}$ stage, $\mathrm{N}$ stage, tumor

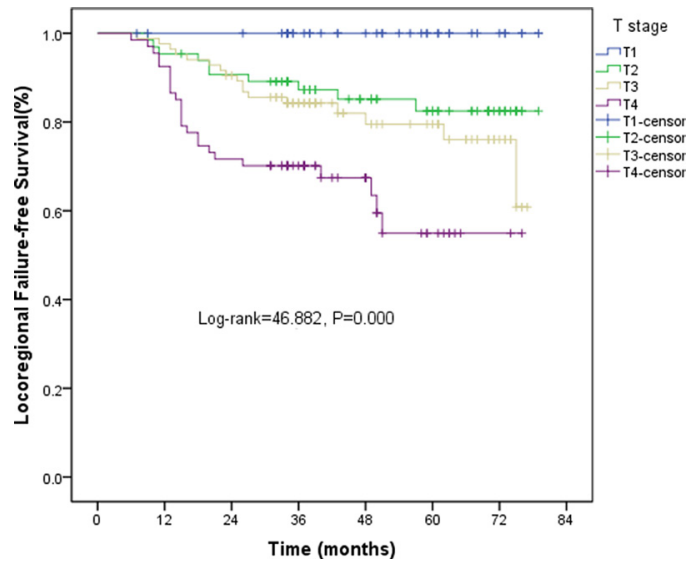

Figure 3: Kaplan-Meier curves of LRFS for T stage.

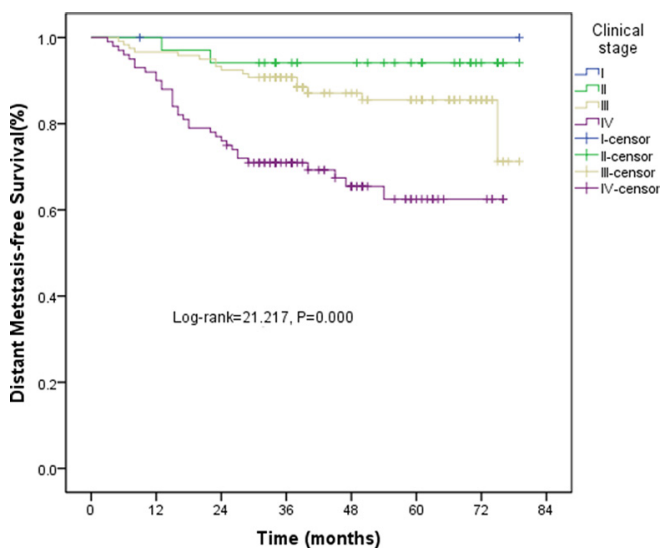

Figure 4: Kaplan-Meier curves of DMFS for clinical stage 
Table 1: Site and incidence of treatment failure

\begin{tabular}{cc}
\hline Sites & Number of patients $(\boldsymbol{n}=\mathbf{6 2})$ \\
\hline Local only & 18 \\
Regional only & 10 \\
Local and regional & 4 \\
Locoregional and distant & 5 \\
Distant only & 5 \\
Lung only & 3 \\
Liver only & 4 \\
Bone only & 13 \\
\hline
\end{tabular}

Table 2: Impact of prognostic factors on treatment outcome by univariate analysis

\begin{tabular}{|c|c|c|c|c|}
\hline Variable & $N$ & 5-year OS & $\chi^{2}$ & $P$ \\
\hline Sex & & & 1.801 & 0.18 \\
\hline Male & 186 & $78 \%$ & & \\
\hline Female & 69 & $85.5 \%$ & & \\
\hline Age (years) & & & 6.314 & 0.12 \\
\hline$\geq 60$ & 66 & $69.7 \%$ & & \\
\hline$<60$ & 189 & $83.6 \%$ & & \\
\hline Histology & & & 2.434 & 0.487 \\
\hline WHO I & 5 & $100 \%$ & & \\
\hline WHO II & 244 & $79.1 \%$ & & \\
\hline WHO III & 6 & $100 \%$ & & \\
\hline T stage & & & 25.008 & $<0.001$ \\
\hline $\mathrm{T} 1$ & 39 & $100 \%$ & & \\
\hline $\mathrm{T} 2$ & 65 & $84.6 \%$ & & \\
\hline $\mathrm{T} 3$ & 84 & $79.8 \%$ & & \\
\hline $\mathrm{T} 4$ & 67 & $64.2 \%$ & & \\
\hline $\mathrm{N}$ stage & & & 16.861 & 0.001 \\
\hline No & 18 & $83.3 \%$ & & \\
\hline N1 & 74 & $87.8 \%$ & & \\
\hline N2 & 117 & $82.1 \%$ & & \\
\hline N3 & 46 & $60.9 \%$ & & \\
\hline Clinical stage & & & 22.622 & $<0.001$ \\
\hline I & 2 & $100 \%$ & & \\
\hline II & 34 & $94.1 \%$ & & \\
\hline III & 119 & $86.6 \%$ & & \\
\hline IV & 100 & $67 \%$ & & \\
\hline Weight loss (kg) & & & 0.134 & 0.715 \\
\hline$\geq 5$ & 43 & $76.7 \%$ & & \\
\hline$<5$ & 211 & $80.6 \%$ & & \\
\hline Combined chemo & & & 0.608 & 0.434 \\
\hline Yes & 231 & $80.9 \%$ & & \\
\hline No & 24 & $72 \%$ & & \\
\hline
\end{tabular}




\begin{tabular}{|c|c|c|c|c|}
\hline Blood group & & & 1.505 & 0.681 \\
\hline A & 72 & $75 \%$ & & \\
\hline B & 55 & $81.8 \%$ & & \\
\hline $\mathrm{AB}$ & 27 & $85.2 \%$ & & \\
\hline $\mathrm{O}$ & 101 & $81.2 \%$ & & \\
\hline Comorbidity & & & 0.873 & 0.35 \\
\hline Yes & 65 & $78.9 \%$ & & \\
\hline No & 190 & $81.3 \%$ & & \\
\hline Tumor response & & & 5.033 & 0.025 \\
\hline $\mathrm{CR}$ & 174 & $83,3 \%$ & & \\
\hline PR & 81 & $72.8 \%$ & & \\
\hline
\end{tabular}

response, and clinical stage were significant predictors for overall survival (Table 2). However, age, T-classification, $\mathrm{N}$-classification and combined chemotherapy were founded to be independent factors of prognosis for overall survival (Table 3).

\section{Toxicity}

Acute toxicities were assessed during treatment and late toxicities with 6 months follow-up (Table 4). No treatment-related death occurred. The most commonly observed acute toxicities included mucositis, skin reactions, xerostomia, leucocytopenia, and weight loss. The incidence of acute mucositis grade $1-2$ was $93.7 \%$ (239/255), with no cases of grade 4 toxicity detected. No grade 3 or 4 skin reactions were occurred within the RT field. The incidence of grade 1-2 leucocytopenia was $91.0 \%$ (232/255). Five patients developed grade 4 leucocytopenia. However, the neutrophil count recovered rapidly following administration of granulocyte colony-stimulating factor (GCSF). No cases of renal function impairment were observed. Overall, 211 patients experienced mild to moderate weight loss.

Dry mouth was the most common late complication, and its severity decreased over time. The degree of xerostomia in most survivors was mild-to-moderate at the last follow-up time. 90 of all patients didn't subjectively complaint of xerostomia. $15.7 \%$ of patients developed unilateral or bilateral hearing impairment and 23 occurred radiation encephalopathy diagnosed by magnetic resonance imaging (MRI) at follow-up.

\section{DISCUSSION}

Primary RT, as the mainstream of treatment, has been used to treat for patients with NPC. Ho [15] described that $2 \mathrm{D}$ techniques was used to deliver radical RT for NPC since the early 1990s. This was devised in the era when CT scans were not available and a shortage of machine time was a common problem in the community. Hence, all planning was done on simulator films using standard orthogonal field arrangements and lead blocks on the basis of anatomic landmarks rather than actual tumor geometry. The local control rates of NPC patients treated with $2 \mathrm{D}$ planning techniques were $80-85 \%$, taking all T-stages together $[16,17]$. With the emergence of the CT simulation and the 3D-TPS, the 3D relationship between the tumor and the surrounding OARs can be observed more vividly. It is obvious that this dose distribution of rectangular-shaped in 2D-RT planning is not ideal and will inevitably lead to undesirable target coverage and the coverage of a large number of normal tissues. A dosimetric study by Chau et al. [18] showed that the conventional 2D planning technique was inadequate in achieving dose coverage in the superior (skull base), posterolateral (parapharyngeal), and inferior regions of the target area, and the high dose areas of OARs. Ng et al. [19], who reviewed 700 patients with NPC, concluded that if target coverage could be improved through the use of a better RT technique, parapharyngeal extension would no longer be a significant prognosticator. Moreover, a quality of life survey showed that xerostomia, dysaudia, dysphagia, and trismus were regarded as the most frequent complications of disease-free NPC survivors treated with conventional 2D-RT techniques [20]. Hence, NPC patients delivered conventional 2D-RT techniques developed serious side effects and experienced very poor quality of life.

With the development of technology, 3D-CRT or IMRT with inverse RT planning should be as the modern RT technique used for NPC. Until the mid-1990s, IMRT has been used for the treatment of different head and neck carcinoma, including NPCs. IMRT techniques can provide better dose distributions for irregular- or concave-shaped target volumes near the OARs. Non-randomized studies demonstrated that compared with $2 \mathrm{D}-\mathrm{RT}$ or $3 \mathrm{D}$-CRT plans, IMRT provided the better tumor coverage and the lower dose of OARs including the central nervous system and parotid glands in the treatment of NPC [21-24]. Single institutional results showed that locoregional control and OS rates of NPC were enhanced by IMRT [25-29]. Despite as a new technology, it is encouraging to improve the therapeutic ratio, whether marginal relapse 
Table 3: Influence of prognostic factors on treatment outcome by Cox proportional hazards models

\begin{tabular}{lcccccc}
\hline \multicolumn{1}{c}{ Variable } & B & SE & Wald & Odds ratio & $\boldsymbol{P}$ & 95\% CI \\
\hline T stage & 0.89 & 0.254 & 12.287 & 2.435 & $<0.001$ & $1.480-4.004$ \\
N stage & 0.864 & 0.246 & 12.313 & 2.373 & $<0.001$ & $1.464-3.845$ \\
Age & 0.04 & 0.014 & 8.291 & 1.041 & 0.004 & $1.013-1.069$ \\
Comb CT & 0.918 & 0.446 & 4.228 & 0.379 & 0.04 & $0.167-0.958$ \\
\hline
\end{tabular}

Note: comb CT combined chemotherapy.

Table 4: Frequencies of the most common acute and late treatment related toxicities by type and grade

\begin{tabular}{llllll}
\hline \multicolumn{1}{c}{ Treatment toxicities } & \multicolumn{1}{c}{ Total } & \multicolumn{1}{c}{ Grade 1 } & \multicolumn{1}{c}{ Grade 2 } & \multicolumn{1}{c}{ Grade 3 } & Grade 4 \\
\hline Acute toxicities, $\mathrm{n}(\%)$ & & & & & \\
$\quad$ Mucositis & $250(98.0)$ & $50(19.6)$ & $189(74.1)$ & $11(4.3)$ & 0 \\
leucocytopenia & $240(94.1)$ & $137(53.7)$ & $95(37.3)$ & $3(1.1)$ & $5(2.0)$ \\
$\quad$ Dematitis & $245(96.1)$ & $214(83.9)$ & $23(9.1)$ & $8(3.1)$ & 0 \\
$\quad$ Xerostomia & $220(886.3)$ & $58(22.7)$ & $147(57.7)$ & $15(5.9)$ & 0 \\
Late toxicities, n (\%) & & & & \\
$\quad$ Xerostomia & $165(64.7)$ & $72(28.2)$ & $82(32.2)$ & $11(4.3)$ & 0 \\
Hearing loss & $40(15.7)$ & $26(10.2)$ & $9(3.5)$ & $5(2.0)$ & 0 \\
Neck fibrosis & $95(37.3)$ & $89(34.9)$ & $6(2.4)$ & 0 & 0 \\
REP & $23(9.0)$ & $15(5.9)$ & $5(2.0)$ & $2(0.7)$ & $1(0.4)$ \\
\hline
\end{tabular}

Note: REP Radiation encephalopathy; ${ }^{*}$ The patients with NPC were evaluated at six months after radiotherapy.

may be caused by the conformation of target coverage and the protection of normal tissue is not determined [30-32]. Though IMRT is the first choice to treat NPC patients, all patients cannot be used for IMRT owning to the lesser machines and more patients. So we designed an alternative therapeutic method to conventional 2D-RT and applied this method in clinical practice according to the actual situation of our hospital.

The dosimetric study showed 4F-CRT technique provided better tumor coverage and OARs sparing [14]. DVH showed that the sharper curves for PGTVnx and PTVnx in the 4F-CRT plans were similar to those in the IMRT. The doses of the target volumes in the 4F-CRT plans were higher than those in the 2D-RT plans. At the same time, the Dmax doses of OARs were within safety limits.

In total, 255 patients accepted the 4F-CRT plans and 231 received concomitant chemotherapy. The 3-year LRFS, PFS, and OS rates were $83.3 \%, 82 \%$, and $82.8 \%$, respectively. The 5-year LRFS, PFS, and OS rates were $76.1 \%, 73.2 \%$, and $76.3 \%$, respectively. Univariate analysis indicated that $\mathrm{T}$ stage, $\mathrm{N}$ stage, tumor response, and clinical stage were significant predictors for OS. However, age, T-classification, N-classification and combined chemotherapy were founded to be independent factors of prognosis for OS. The predominant acute toxicities were mucositis, skin reactions, xerostomia, leucocytopenia, and weight loss; most were mild or moderate. Hence, the long-term efficacy of 4F-CRT is satisfactory and its acute toxicities are tolerable. The results demonstrated that better clinical outcome and quality of life for NPC patients were obtained 4F-CRT due to the dosimetric advantage.

To the best of our knowledge, the present study is the first designed to test the outcome and long-term efficacy of 4F-CRT in patients with NPC. This regimen achieved good treatment results and demonstrated an acceptable acute toxicity profile. Furthermore, late complications (including severe xerostomia, hearing impairment, and temporal lobe necrosis) were less frequently observed in patients undergoing 4F-CRT than in those undergoing conventional 2D-RT. However, our findings are limited by virtue of being from a phase II clinical trial, restricted to China. The sample size was small.

\section{MATERIALS AND METHODS}

\section{Patients and pretreatment evaluation}

From November 2007 to December 2011, a total of 255 consecutive patients with newly histologically diagnosed, non-metastatic NPC received prospectively treatment with 4F-CRT at the Department of Radiation Oncology, Zhejiang Cancer Hospital (Hangzhou, People's Republic of China). The patients were aged 21-81 years, and 186 men and 69women were included. All patients underwent pretreatment evaluation which included a 
complete history, physical examination, hematology and biochemistry profiles, chest radiography, abdominal sonography, bone scan, and magnetic resonance imaging of the nasopharynx. All patients were staged according to the 2010 AJCC staging system [33]. Five patients had type I, 244 had type II, and 6 had type III tumors, according to the World Health Organization's classification of tumor histology [34]. The characteristics of the patients are summarized in Table 5.

\section{Delineation for the tumor volume}

All patients were immobilized in the supine position with thermoplastic masks. Computed tomography scans with intravenous contrast, using $2.5 \mathrm{~mm}$ slices from the head to a level $2 \mathrm{~cm}$ below the sternoclavicular joints were performed for planning. Target volumes were delineated according to the recommendations by the International Commission on Radiation Units and Measurements (ICRU) CTV delineation protocol for head and neck malignancies $[35,36]$.

Gross tumor volume (GTV) referred to the tumor extent found in clinical and imaging examinations. The primary tumor extent including the metastatic retropharyngeal lymph nodes (RLNs) was named as GTVnx, and the metastatic lymph nodes of the neck as GTVnd.

Clinical target volume (CTV) was defined individually according to GTV, and risk region potentially involved around the nasopharyngeal cavity. The CTV for GTVnx included CTVnx for the high-risk clinical target volume and CTV1 for potentially invaded extension. CTVnx was defined as GTVnx plus a $7 \mathrm{~mm}$ margin, encompassing the entire nasopharyngeal mucosa plus $5 \mathrm{~mm}$ submucosal volume. For CTV1, potentially involved anatomic regions, including the whole nasopharyngeal cavity, the anterior one- to two-thirds of the clivus (when invaded, the whole clivus should be covered), the skull base, the pterygoid plates, the parapharyngeal space, the inferior sphenoid sinus (the whole sphenoid sinus should be covered for stages T3 and T4), the posterior onequarter to one-third of the nasal cavity, and the maxillary sinus, were included. Level Ib was considered high risk in patients with metastatic lymph nodes in level IIa, and any lymph node drainage pathways containing metastatic lymph nodes were considered high risk. Prophylactic low risk neck irradiation areas were referred as CTV2, including levels IV and $\mathrm{Vb}$ without metastatic cervical lymph nodes.

The planning target volume (PTV) was constructed automatically based on each volume with an additional 3-mm margin in three dimensions, allowing for setup variability. All of the PTVs including PGTVnx, PTVnx, PTV1 and PTV2, should not be delineated outside of the skin surface. Figure 5 demonstrates the delineations of target volumes.

Critical normal structures, including the brainstem, spinal cord, parotid glands, optic nerves, chiasm, lens, eyeballs, temporal lobes, temporomandibular joints, mandible, and hypophysis were contoured and set as OARs during optimization.
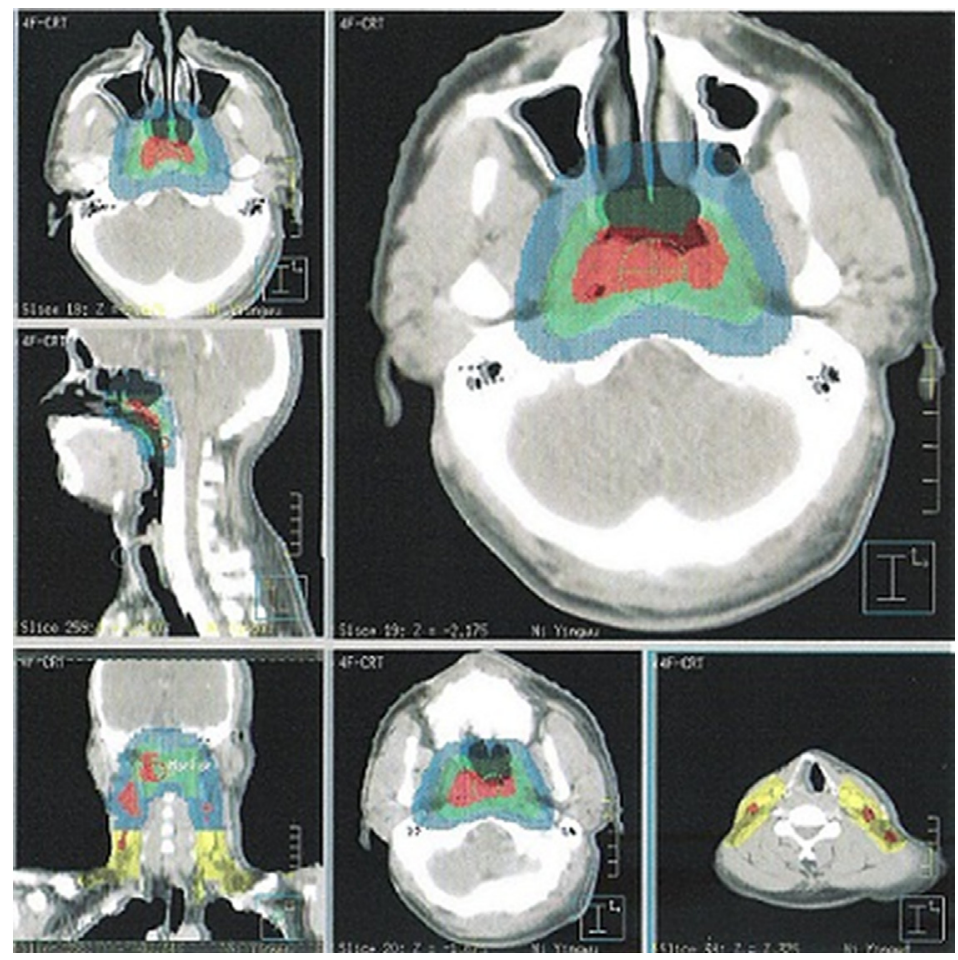

Figure 5: Selected CT slides for demonstrating the delineation of target volumes. (Red area: PGTVnx and GTVnd; Green area: PTVnx; Blue area: PTV1; Yellow area: PTV2). 
Table 5: The clinicopathological characteristic of the 255 patients enrolled in the study

\begin{tabular}{|c|c|}
\hline Patient characteristic & Number of patients $(\%)$ \\
\hline \multicolumn{2}{|l|}{ Sex } \\
\hline Male & $186(72.9 \%)$ \\
\hline Female & $69(27.1 \%)$ \\
\hline \multicolumn{2}{|l|}{ Age (years) } \\
\hline Median (range) & 52 \\
\hline$\geq 60$ & $66(25.9 \%)$ \\
\hline$<60$ & $189(74.1 \%)$ \\
\hline \multicolumn{2}{|l|}{ WHO histologic type } \\
\hline II & $5(2 \%)$ \\
\hline III & $244(95.7 \%)$ \\
\hline Other & $6(2.3 \%)$ \\
\hline \multicolumn{2}{|l|}{ T stage } \\
\hline $\mathrm{T} 1$ & $39(15.3 \%)$ \\
\hline $\mathrm{T} 2$ & $65(25.5 \%)$ \\
\hline $\mathrm{T} 3$ & $84(32.9 \%)$ \\
\hline $\mathrm{T} 4$ & $67(26.3 \%)$ \\
\hline \multicolumn{2}{|l|}{ N stage } \\
\hline No & $18(7.1 \%)$ \\
\hline N1 & $74(29 \%)$ \\
\hline $\mathrm{N} 2$ & $117(45.9 \%)$ \\
\hline N3 & $46(18 \%)$ \\
\hline \multicolumn{2}{|l|}{ UICC stage } \\
\hline $\mathrm{I}$ & $2(7.8 \%)$ \\
\hline II & $34(13.3 \%)$ \\
\hline III & $119(46.7 \%)$ \\
\hline IV & $10039.2 \%)$ \\
\hline \multicolumn{2}{|l|}{ Combined chemotherapy } \\
\hline Yes & $231(90.6 \%)$ \\
\hline No & $24(9.4 \%)$ \\
\hline
\end{tabular}

\section{Radiotherapy techniques}

Treatment, given in three phases, was performed as formerly described [14]. Four facio-cervical (anterior and posterior facio-cervical and two lateral opposing faciocervical) fields were irradiated for CTV1 with $34 \mathrm{~Gy} / 17$ $\mathrm{F}$ and a lower cervical anterior tangent field was used for CTV2 with $34 \mathrm{~Gy} / 17 \mathrm{~F}$ for phase I treatment. The eyes, optic nerves, temporal lobe, and brain stem were shielded as much as possible. For phase II treatment, treatment could be continued using the two lateral opposing facio-cervical fields but with shrinkage of fields to avoid the spinal cord and superior neck, and superior-lower neck lymphatics with electron fields. A dose of 26 Gy was given to CTV1, while a dose of 20 Gy was used for CTV2. For phase III treatment, bilateral preauricular fields covered CTVnx with a dose of $10 \mathrm{~Gy}$. The eyes, optic nerves, and brain stem were shielded.

\section{Chemotherapy}

Overall, 231 patients were eligible for chemotherapy as they met the following criteria: ECOG performance status $\leq 2$, white blood cell count $\geq 4000$ cells $/ \mu \mathrm{L}$, and platelet count $>10,000 / \mu \mathrm{L}$. In concurrent CRT, two courses of chemotherapy were planned, consisting of cisplatin $\left(30 \mathrm{mg} / \mathrm{m}^{2} /\right.$ day) and $5-\mathrm{Fu}\left(500 \mathrm{mg} / \mathrm{m}^{2} /\right.$ day $)$ for 3 days. In the following adjuvant chemotherapy, two cycles of chemotherapy were planned, consisting of cisplatin and 5-Fu.

\section{Plan evaluation}

Plans were compared by target coverage according to the cross-section dose distribution and the dose-volume histogram (DVH) of targets. Parameters of the DVH were evaluated as following: 1) the doses received by the $95 \%$ 
and 90\% volumes of PTV (D95 and D90), maximum PTV dose (Dmax), minimum PTV dose (Dmin), mean PTV dose; 2) maximum OARs dose and the volume of OARs received high dose. Moreover, the time was measured between the patient entering and exiting the treatment room for completing each of three plans. This included time for patient to change, set-up time, EPID time (once weekly), and the actual treatment time.

\section{Toxicity and survival evaluation}

Toxicity was evaluated using the common toxicity criteria of the National Cancer Institute. Survival was calculated from the date of diagnosis to the date of most recent follow-up, recurrence, or death. The pattern of failure was defined according to the first site of failure: local failure was defined as recurrence of the primary tumor or metastasis to regional lymph nodes; and distant failure indicated metastasis to any site beyond the primary tumor and regional lymph nodes.

\section{Statistical analysis}

Survival curves were performed using KaplanMeier product-limit methods. Comparison of the curves was performed using the log-rank test. Multivariate analysis to identify significant prognostic factors was accomplished using Cox regression models. Hazard ratios (HR) and 95\% confidence intervals (CI) were calculated for each prognostic factor to identify those with statistical significance. IBM SPSS statistics version 19.0 software was used for all data analysis. Statistical significance was indicated at $\mathrm{P}<0.05$. Survival time was calculated from the date of diagnosis to the most recent follow-up or to the date of relapse (event-free, local recurrence-free, or distant metastasis-free) or death (overall survival). After recurrence or metastasis, patients were given salvage therapy as determined by their physicians.

\section{CONCLUSIONS}

This study on 4F-CRT used for the treatment of NPC had indicated that the superiority of 4F-CRT in achieving tumor coverage, dose homogeneity, and sparing of normal organ. In our hospital, this technique had been accepted as a treatment method to replace conventional 2D-RT in the treatment of NPC. The major superiority of 4F-CRT is to reduce the radiation dose of several OARs. Moreover, this regimen demonstrates better long-term efficacy and an acceptable acute toxicity profile. This study was a single center trial and has all the limitations of single center.

\section{ACKNOWLEDGMENTS AND FUNDING}

This study was supported by grants from the Medical Science Foundation of Zhejiang Health Bureau
(No. 2013KYB033, No. 2009B026, No. 2006A016, No. 2005B012, No. 2004B014), National Natural Science Foundation of China (No. 81502647).

\section{CONFLICTS OF INTEREST}

The authors have no actual or potential conflicts of interest to declare.

\section{REFERENCES}

1. Jemal A, Bray F, Center MM, Ferlay J, Ward E, Forman D. Global cancer statistics. CA Cancer J Clin. 2011; 61:69-90.

2. Cao SM, Simons MJ, Qian CN. The prevalence and prevention of nasopharyngeal carcinoma in China. Chin J Cancer. 2011; 30:114-119.

3. Lee AW, Foo W, Law SC, Poon YF, O SK, Tung SY, Sze WM, Chappell R, Lau WH, Ho JH. Staging of nasopharyngeal carcinoma: from Ho's to the new UICC system. Int J Cancer. 1998; 84:179-87.

4. Al-Sarraf M, Reddy MS. Nasopharyngeal carcinoma. Curr Treat Options Oncol. 2002; 3:21-32.

5. Chua DT, Ma J, Sham JS, Mai HQ, Choy DT, Hong MH, Lu TX, Au GK, Min HQ. Improvement of survival after addition of induction chemotherapy to RT in patients with early-stage nasopharyngeal carcinoma: subgroup analysis of two phase III trials. Int J Radiat Oncol Biol Phys. 2006; 65:1300-1306.

6. Lee AW, Sze WM, Au JS, Leung SF, Leung TW, Chua DT, Zee BC, Law SC, Tea PM, Tung SY, Kwong DL, Lau WH. Treatment results for nasopharyngeal carcinoma in the modern era: the Hong Kong experience. Int J Radiat Oncol Biol Phys. 2005; 61:1107-1116.

7. Yi JL, Gao L, Huang XD, Li SY, Luo JW, Cai WM, Xiao JP, Xu GZ. Nasopharyngeal carcinoma treated by radical radiotherapy alone: ten-year experience of a single institution. Int J Radiat Oncol Biol Phys. 2006; 65:161-168.

8. Low WK, Fong KW. Long-term hearing status after radiotherapy for nasopharyngeal carcinoma. Auris Nasus Larynx. 1998; 25:21-24.

9. Medndenhall WM, Morris CG, Hinerman RW, Malyapa RS, Amdur RJ. Definitive radiotherapy for nasopharyngeal carcinoma. Am J Clin Oncol. 2006; 29:622-627.

10. Intensity Modulated Radiation Therapy Collaborative Working Group. Intensity-modulated radiotherapy: current status and issues of interest. Int J Radiat Oncol Biol Phys. 2001; 51:880-914.

11. Ezzell GA, Galvin JM, Low D, Palta JR, Rosen I, Sharpe MB, Xia P, Xiao Y, Xing L, Yu CX, IMRT subcommittee and AAPM Radiation Therapy commitee. Guidance document on delivery, treatment planning, and clinical implementation of IMRT: report of the IMRT Subcommittee of the AAPM Radiation Therapy Committee. Med Phys. 2003; 30:2089-2115. 
12. Mendenhall WM, Amdur RJ, Palta JR. Intensity-modulated radiotherapy in the standard management of head and neck cancer: promises and pitfalls. J Clin Oncol. 2006; 24:2618-23.

13. Kam MK, Leung SF, Zee B, Chau RM, Suen JJ, Mo F, Lai M, Ho R, Cheung KY, Yu BK, Chiu SK, Choi PH, Teo PM, et al. Prospective randomized study of intensitymodulated radiotherapy on salivary gland function in earlystage nasopharyngeal carcinoma patients. J Clin Oncol. 2007; 25:4873-79.

14. Wang FZ, Fu ZF, Wang L, Piao YF, Hua YH, Chen WJ, $\mathrm{Xu}$ Min. Technical and dosimetric study of four faciocervical carcinoma. Chinese Journal of Biomedical Engineering. 2012; 21:129-33.

15. Ho JHC. Nasopharynx. In: Halnan KE, editor. Treatment of cancer, Chapman and Hall: London. 1982; 249-268.

16. Teo P, Yu P, Lee WY, Leung SF, Kwan WH, Yu KH, Choi P, Johnson PJ. Significant prognosticators after primary radiotherapy in 903 nondisseminated nasopharyngeal carcinoma evaluated by computer tomography. Int J Radiat Oncol Biol Phys. 1996; 36:291-304.

17. Lee AW, Poon YF, Foo W, Law SC, Cheung FK, Chan DK, Tung SY, Thaw M, Ho JH. Retrospective analysis of 5037 patients with nasopharyngeal carcinoma treated during 1976-1985: overall survival and patterns of failure. Int J Radiat Oncol Biol Phys. 1992; 23:261-70.

18. Chau RM, Teo PH, Choi PH, Cheung KY, Lee WY. Three-dimensional dosimetric evalution of a conventional radiotherapy technique for treatment of nasopharyngeal carcinoma. Radiother and oncol. 2001; 58:143-53.

19. Ng WT, Chan SH, Lee AW, Lau KY, Yau TK, Hung WM, Lee Mc and Choi CW. Parapharyngeal extension of nasopharyngeal carcinoma: still a significant factor in era of modern radiotherapy? Int J Radiat Oncol Biol Phys. 2008; 72:1082-9.

20. Cengiz M, Ozyar E, Esassolak M, Altun M, Akmansu M, Sen M, Uzel O, Yavuz A, Dalmaz G, Uzal C, Hicsonmez A, Sarihan S, Kaplan B, et al. Assessment of quality of life of nasopharyngeal carcinoma patients with EORTC QLQ-C30 and H\&N-35 modules. Int J Radiat Oncol Biol Phys. 2005, 63:1347-53.

21. Kam MK, Chau RM, Suen J, Choi PH, Teo PM. Intensitymodulated radiotherapy in nasopharyngeal carcinoma: dosimetric advantage over conventional plans and feasibility of dose escalation. Int J Radiat Oncol Biol Phys. 2003; 56:145-57.

22. Hunt MA, Zelefsky MJ, Wolden S, Chui CS, LoSasso T, Rosenzweig K, Chong L, Spirou SV, Fromme L, Lumley M, Amols HA, Ling CC, Leibei SA. Treatment planning and delivery of intensity-modulated radiation therapy for primary nasopharynx cancer. Int J Radiat Oncol Biol Phys. 2001; 49:623-32.

23. Cheng JC, Chao KS, Low D. Comparison of intensity modulated radiation therapy (IMRT) treatment techniques for nasopharyngeal carcinoma. Int J Cancer. 2001; 96:126-31.
24. Xia P, Fu KK, Wong GW, Akazawa C, Verhey LJ. Comparison of treatment plans involving intensitymodulated radiotherapy for nasopharyngeal carcinoma. Int J Radiat Oncol Biol Phys. 2000; 48:329-37.

25. Fang FM, Chien CY, Tsai WL, Chen HC, Hsu HC, Lui CC, Huang TL, Huang HY. Quality of life and survival outcome for patients with nasopharyngeal carcinoma receiving three-dimensional conformal radiotherapy vs. intensitymodulated radiotherapy — a longitudinal study. Int J Radiat Oncol Biol Phys. 2008; 72:356-64.

26. Wolden SL, Chen WC, Pfister DG, Kraus DH, Berry SL, Zelefsky MJ. Intensity-modulated radiation therapy (IMRT) for nasopharynx cancer: update of the Memorial SloanKettering experience. Int J Radiat Oncol Biol Phys. 2006; 64:57-62.

27. Kwong DL, Sham JS, Leung LH, Cheng AC, Ng WM, Kwong PW, Lui WM, Yau CC, Wu PM, Wei W, Au G. Preliminary results of radiation dose escalation for locally advanced nasopharyngeal carcinoma. Int J Radiat Oncol Biol Phys. 2006; 64:374-81.

28. Lee AW, Lau KY, Hung WM, Ng WT, Lee MC, Choi CW, Chan CC, Tung R, Cheng PT, Yau TK. Potential improvement of tumor control probability by induction chemotherapy for advanced nasopharyngeal carcinoma. Radiother Oncol. 2008; 87:204-10.

29. Lee SW, Back GM, Yi BY, Choi EK, Ahn SD, Shin SS, Kim JH, Kim SY, Lee BJ, Nam SY, Choi SH, Kim SB, Park JH. Preliminary results of a phase I/II study of simultaneous modulated accelerated radiotherapy for nondisseminated nasopharyngeal carcinoma. Int J Radiat Oncol Biol Phys. 2006; 65:152-60.

30. Mendenhall WM, Mancuso AA. Radiotherapy for head and neck cancer; is the 'next level' down? Int J Radiat Oncol Biol Phys. 2009; 73:645-6.

31. Mendenhall WM, Amdur RJ, Palta JR. Intensity-modulated radiotherapy in the standard management of head and neck cancer: promises and pitfalls. J Clin Oncol. 2006; 24:2618-23.

32. Harari PM. Beware the swing and a miss: baseball precautions for conformal radiotherapy. Int J Radiat Oncol Biol Phys. 2008; 70:657-9.

33. SB E, DR B, CC C. AJCC Cancer Staging Manual, 7th Edition. In: Springer NY, ed. 2010.

34. Shanmugaratnam K, Sobin LH. The World Health Organization histological classification of tumors of the upper respiratory tract and ear. A commentary on the second edition. Cancer. 1993; 71:2689-97.

35. International Commission on Radiation Units and Measurements. Prescribing, recording, and reporting photon beam therapy. Bethesda: ICRU, 1993.

36. International Commission on Radiation Units and Measurements. Prescribing, recording, and reporting photon beam therapy (Supplementary to ICRU report 50) . Bethesda: ICRU, 1999. 